\title{
Decay of temporary teeth and the role of pediatric dentist in its treatment
}

\author{
Mirel TOMA ${ }^{1}$, Florentina RADU ${ }^{2}$, Gabriel $\mathrm{CIOCHINDA}^{1}$, Cristina Nicoleta $\mathrm{MIHAI}^{1}$, \\ Sorin Nicolae POPESCU ${ }^{1}$, Viorel Stefan PERIEANU ${ }^{1}$, lleana IONESCU ${ }^{1}$, \\ Madalina Violeta PERIEANU ${ }^{1}$, Magdalena Natalia DINA ${ }^{1}$, Olivia POPOVICIU ${ }^{1}$, Raluca COSTEA ${ }^{2}$, \\ Liliana BURLIBASA ${ }^{3}$, Corina Marilena CRISTACHE ${ }^{1}$, Mihaela Rodica PAUNA ${ }^{1}$, \\ Luminita OANCEA ${ }^{1}$, Rodica LUCA $^{1}$ \\ 1"Carol Davila" University of Medicine and Pharmacy, Bucharest, Romania \\ ${ }^{2}$ Private dental practice, Bucharest, Romania \\ ${ }^{3}$ Faculty of Biology, University of Bucharest, Romania
}

\begin{abstract}
Introduction. The therapeutic approach of deep carious lesions in the temporary teeth represents an extremely complex problem for pediatric dentists, both in terms of their instrumentation and in terms of collaboration with children in specialized treatment, but also with their parents.

Purpose. In this material we tried to present as briefly as possible the role of the pediatric dental specialist in the treatment of deep carious lesions existing in the temporary dentition.

Material and method. The study was carried out with the help of 41 dentists in Romania, from September 10 to October 10, 2019.

Results and discussions. Centralized responses create a clear picture of how practitioners understand the importance of dental caries treatment in temporary teeth.

Conclusions. Maintaining temporary teeth on the arches until the eruption of the definitive counterparts, plays an important role in maintaining the length and shape of the dental arches, as well as in preventing the occurrence of malocclusions.
\end{abstract}

Keywords: deep carious lesions, temporary dentition, Stepwise excavation technique

\section{INTRODUCTION}

The most common disease of the dento-maxillary system of the individual of our society is represented by tooth decay. The frequency of tooth decay in all individuals in Romania, regardless of age, places it at the forefront of all diseases (in practice, we talk about a frequency of over $98 \%$ ) (1-5).
Specifically, tooth decay is present both in the temporary dentition (preschool age) with a frequency ranging from $40-60 \%$, it reaches the age of the mixed dentition (it is also known as the school age) to comprise $95-97 \%$ of individuals, affecting even from the first months, in an impressive frequency, the first permanent teeth (6-years molars), so that later it gradually includes, age related, other teeth from the permanent dentition (1-5). 
But what gives tooth decay the character of social disease is not just the large number of affected individuals, but also the degree of affectation of an individual, namely its intensity (we find tooth decay since the growth age, and can affect more than $50 \%$ of the teeth existing) (1-5).

\section{PURPOSE}

Tooth decay is considered by the dental specialists to be a chronic disease, with a symptomatic and insidious evolution, and which can lead on short or long term to pulp and periodontal septic complications, which constitute a permanent threat of spreading the infection in neighboring regions and triggering and maintaining at distance some important systemic diseases (also known as outbreak diseases) (1-5).

Destructive, progressive, but also irreversible lesion, simple and/or complicated caries is the most common cause of breaking the morphofunctional balance between the constituent elements of the dento-maxillary system (1-5).

But, besides the simple and / or complicated tooth decay that we have already mentioned, within the population we find, from the age of growth, a multitude of abnormal reports between the different constituent elements of the denomaxillary system.

The frequency of dento-maxillary abnormalities of people in growing age, in addition to an impressive frequency of carious lesions with their complications untreated on time and correctly, especially at the temporary dentition, causes a severe dento-maxillary morphofunctional imbalance.

Thus, the interdependence between the dento-maxillary anomalies and the simple and/or complicated carious lesions localizated in both temporary and permanent dentition on the one hand, but also their association with the periodontal resorption of inflammatory or mechanical type on the other hand make the activity of the dental practitioner, including the pediatric dentist, not be limited only to detect and treat of an condition as such. Specifically, the dentist, including the pediatric dentist, must consider the entire state of dento-maxillary system. The role of the dentist, including the pediatric dentist, is to ensure the restoration and maintenance of a morphofunctional balance as long as possible, between the different components of the dento-maxillary system (1-5).

But a more special problem faced by the practitioner working in the field of pediatric dentistry, refers mainly to the therapeutic approach of tem- porary teeth, in case of superficial and/or deep carious lesions. This therapeutic approach of carious lesions (superficial or deep) in the temporary dentition must take into account not only the modern principles and techniques of preparation and instrumentation of these carious lesions, but also the rapid evolution in time of the materials used in dentistry (both materials for the preservation and maintenance of the pulp vitality, as well as materials for the restoration of coronary integrity), which is in fact the objective of this material $(1-5)$.

\section{MATERIAL AND METHOD}

As mentioned on other occasions, pediatric dentistry represents that branch of dental medicine (dentistry), which deals with specialized treatments, performed for both children and adolescents (6-15).

And if we should take into account the balanced content of the job description of a pediatric dentist, this should include not only ensuring the oral health of children and adolescents, but also providing theoretical and practical notions of oral and dental education to their parents. These educational aspects, which are mainly addressed to adults (parents and/or guardians of children and adolescents that the pediatric dentist has in treatment), are essential elements of the activity of the pediatric dentist, elements that must be approached with special attention and discretion, in the purpose of establishing firm collaborations based mainly on trust.

Thus, as already mentioned in the beginning of this report, children and adolescents often develop deep carious lesions (children at the level of the temporary dentition and adolescents at the level of the definitive dentition), on the one hand due to an extremely poor oral or dental hygiene and, on the other hand, due to an exaggerated consumption of foods with a high sugar content. Untreated in a timely manner, these carious lesions, initially in an incipient stage, get worse becoming deep carious lesions that can often involve dental pulp (6-15).

Despite both modern preventive technologies and awareness of these young patients and their parents about the importance of maintaining functional tooth units on dental arches, many teeth are lost prematurely due to these untreated or incorrectly treated caries. Basically, keeping a temporary tooth on the dental arch until the permanent tooth erupts is of crucial importance in maintaining the size and shape of the dental arch (6-15). 
As treatment alternatives, it is known that pulpotomy and pulpectomy are commonly used as pulpal therapeutic alternatives, in an attempt to prevent premature loss of teeth, especially dental structures belonging to the temporary dentition. Thus, the Stepwise excavation technique is a treatment method for deep cavities, used to reduce the risk of opening the pulp chamber, especially in molars belonging to the temporary dentition. Basically, this Stepwise method of excavation avoids the exposure of the dental pulp, by excavating the peripheral region of the carious process, applying an insulating material and a provisional coronary filling and waiting for a longer period of time, a few months, for the completion of dental repair processes. Subsequently, the carious process is excavated in the central region, with the definitive coronary filling (glassionomer cement, composite diacrylic resin, etc.) being applied (6-15).

Starting from these notions mentioned above, we composed a questionnaire made of 7 questions, which we applied to a number of 41 dentists, who work in the private environment in various urban regions of Romania, more precisely in big cities, such as Bucharest, Constanta, Pitesti, Brasov, Sibiu, Alexandria, Turnu-Severin. The study, even if it was preliminary, was conducted between September 10 and October 10, 2019.

All the subjects involved in the study ranged in age from 33 to 67 years, being distributed as follows: 27 of the subjects were female $(65.85 \%)$, while the remaining 14 subjects were male $(34,15 \%)$ (Fig. 1).

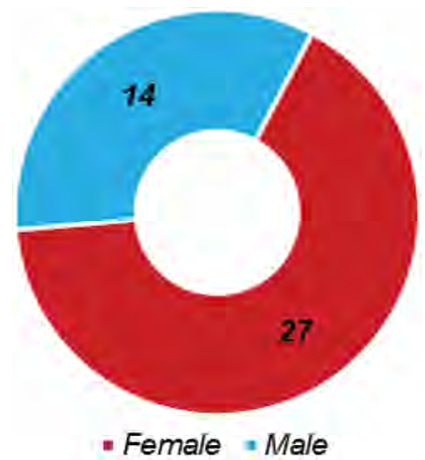

FIGURE 1. Gender distribution of subjects included in study

The questionnaire applied to the study group was as follows:

1. The tooth decays are considered by the specialists in the field as? $\boldsymbol{a}$. The most common dis- ease of the dento-maxillary system for the people of our society; $\boldsymbol{b}$. A chronic disease, with a symptomatology and an insidious evolution; c. Can cause on short of long term pulpal and periodontal septic complications, which constitute a permanent threat of spreading the infection in the neighboring regions and of remote onset and maintenance of important systemic diseases?

\section{Correct answers: $a, b, c$.}

2. The frequency of dento-maxillary abnormalities of persons in growing age, in addition to an impressive frequency of carious lesions with their complications not treated on time and correctly, may lead to the following problems? a. They cause a severe dento-maxillary morphofunctional imbalance; $\boldsymbol{b}$. Cause people severe hormonal imbalances; $c$. They produce accentuated growth imbalances of the upper limbs compared to the lower limbs.

\section{Correct answer: $a$.}

3. Pediatric dentistry represents that branch of dental medicine that deals with? $\boldsymbol{a}$. The study of periodontal diseases; $\boldsymbol{b}$. Specialized treatment of adults and geriatric patients; c. Specialized treatments, performed for both children and adolescents.

\section{Correct answer: $c$.}

4. The role of the pediatric dentist consists of? a. Ensures the restoration and maintenance of a morphofunctional balance as long as possible, between the different components of the dento-maxillary system; $\boldsymbol{b}$. Ensures the implant-prosthetic rehabilitation of the existing edentations; $c$. Ensures the implementation of theoretical and practical notions of oro-dental education for parents of children and adolescents, which specialists in pediatric dentistry provide specialized treatment.

\section{Correct answers: $a, c$.}

5. Children and adolescents often develop deep carious lesions (children at the level of the temporary dentition and adolescents at the level of the definitive dentition) due to? $\boldsymbol{a}$. A very precarious oro-dental hygiene; $\boldsymbol{b}$. To an exaggerated consumption of foods with a high sugar content; c. Some long-term treatments with statin class drugs?

\section{Correct answers $a, b$.}

6. Stepwise excavation technique represents? $\boldsymbol{a}$. A method of treating deep cavities; $\boldsymbol{b}$. It is used to reduce the risk of opening the pulp chamber, especially in molars belonging to the temporary 
dentition; c. Is a treatment method identical to pulpotomy and pulpectomy.

\section{Correct answers: $\boldsymbol{a}, \boldsymbol{b}$.}

\section{RESULTS AND DISCUSSIONS}

About the way in which tooth decay is regarded as a condition by the study participants, 36 of them (representing $87.80 \%$ ) answered correctly (variants $\mathrm{a}, \mathrm{b}$ and $\mathrm{c}$ ), while 5 of them (representing $12.19 \%$ ) considered that they cannot generate septic complications in the neighboring regions (only variants $a$ and $b$ answered) (Fig. 2).

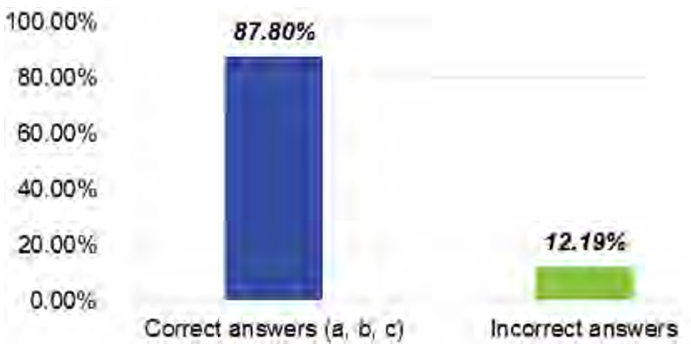

FIGURE 2. The way tooth decay is viewed by the specialists included in the study

To the question related to the effect of the anomalies frequency along with the increased frequency of carious lesions, all study participants answered correctly - variant a.

In relation to the definition of pediatric dentistry, most respondents answered correctly (39 representing 95.12\%), while only 2 respondents answered incorrectly, we can put this fact on account of age but also of the fatigue accumulated as a result of a busy work program of the respondents (Fig. 3).

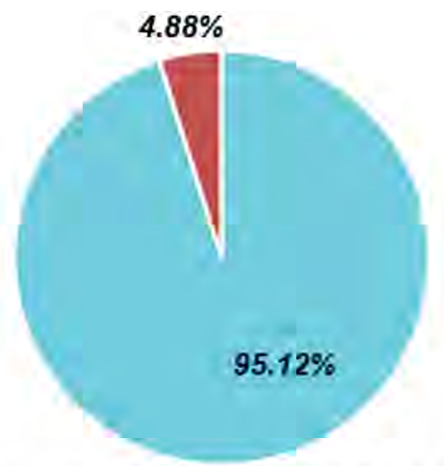

\footnotetext{
- Specialized treatments for children and adolescents

- Incorrect answer
}

FIGURE 3. Correct understanding of pediatric dentistry term

Concerning the role of the pediatric dentist, 31 of the practitioners included in the study (rep- resenting 75.61\%) answered correctly (variants a and c), and only 10 practitioners (representing $24.39 \%$ ) correctly considered only the answer variant a. (Fig. 4).

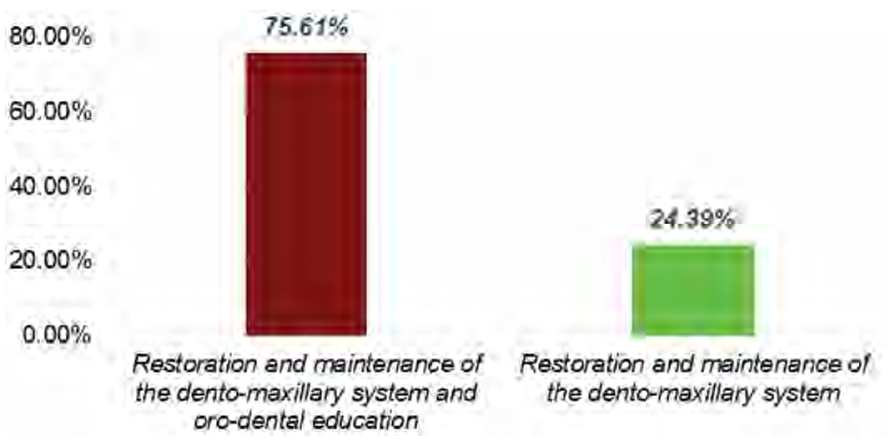

FIGURE 4. The role of the pediatric dentist

The analysis of the answers to the 5th question, related to the causes that induce the deep carious lesions in children and adolescents, showed that all the specialists included in the study know very well this problem.

At the last question of the study regarding the Stepwise excavation technique, most practitioners (35 representing $85.37 \%$ ) answered correctly variants $a$ and $b$, while only 6 practitioners (representing $14.63 \%$ ) answered incorrectly including among the variants variant c (Fig. 5).

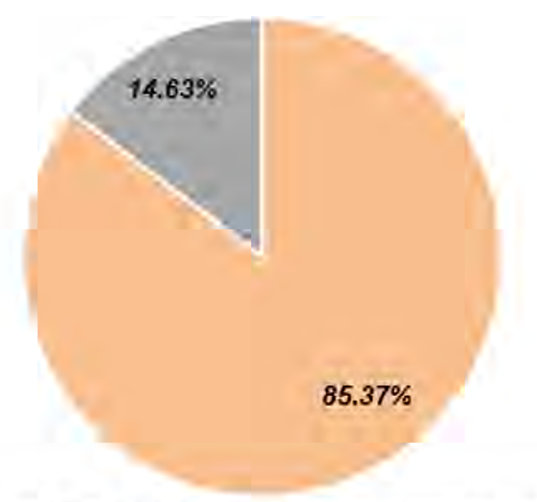

Deep cavities treating method, reduce the risk of opening the pulp chamber - Treatment method identical to pulpotomy and pulpectomy

FIGURE 5. Knowing of Stepwise excavation technique

An analysis of the treatment methods used in the case of temporary tooth decay revealed two patterns of approach to this type of pathology (16). On the one hand, the restorative model that involves stopping the caries process through mechanical procedures and replacing the affected tissues, on the other hand, the preventive model, which involves minimally invasive treatments corroborated with the application of remineralizing 
agents. Regardless of the method chosen, either the method described in this article, or the two methods described in the literature, of particular importance remain both the periodic check-ups, but especially the awareness of the children and parents of the importance of the dental treatments and the periodic checks (17-23).

\section{CONCLUSIONS}

The analysis of the answers led to the some important conclusions.

Most of the dental practitioners involved in the study (over $85 \%$ ) have a strong theoretical knowledge regarding both the therapeutic approach of superficial and deep carious lesions from both temporary and permanent dentition. This is relatively simple to explain, taking into account the fact that these theoretical notions have been taught from the faculty, forming the basis of pediatric dentistry (pedodontics).

However, there is an extremely small percentage of the dentists involved in the study (under $5 \%$ ), which make a huge confusion between periodontology and pedodontics, an aspect that we, the authors, could not explain.

Over $2 / 3$ of the subjects included in the study are aware of the fact that the duties of the pedi- atric dentist are not only limited to practical activities, but also to educational activities for both children and adolescent patients and their parents.

Working with children is often difficult, and treating deep tooth decay is a real challenge. The main problem of these treatments is the diagnosis. Practically, even after a correct diagnosis, the treatment protocol, which often involves isolation, instrumentation, is difficult to follow, in order to ensure the preservation of the tooth without further complications. Many times, the treatment remains incomplete either due to the lack of experience of the pediatric dentist, or, most of the times, due to an uncooperative child or parents.

Many pediatric dentists prefer as a treatment alternative the extraction of the tooth with pulp pathology, to avoid all the problems that it can generate over time.

Knowing the importance of maintaining temporary teeth on the arches, but also their role in maintaining the length and shape of the arch, as well as preventing malocclusions, temporary teeth should be maintained, until the eruption of the permanent tooth counterpart.

\section{Acknowledgement}

In this article, all the authors have equal contribution with the first author.

Conflict of interest: none declared Financial support: none declared

\section{REFERENCES}

1. Gall II. Asistenţa stomatologică. Bucureşti: Ed. Didactică şi Pedagogică, 1971.

2. Miyasaki-Ching CM. Elemente clinice de stomatologie. Bucureşti: Ed. All Educational, 2001.

3. Zarnea L. Pedodonţie. Bucureşti: Ed. Didactică şi Pedagogică, 1993.

4. Rosenstiel SF, Land MF, Fujimoto J. Contemporary fixed prosthodontics. 4th Edition. St. Louis: Mosby Elsevier, 2006.

5. Anusavice KJ. Dental materials. Philips' Science 11th Edition. St. Louis: Saunders Elsevier, 2003.

6. McDonald RE, Avery DR, Dean JA. Treatment of deep caries, vital pulp exposure and pulpless teeth. In: McDonald RE, Avery DR, Dean JA, Dentistry for the Child and Adolescent. 8th ed. St. Louis: Mosby Elsevier; 2007: 396.

7. Waterhouse PJ, Whitworth JM, Camp JH, Fuks AB. Pediatric endodontics: Endodontic treatment for the primary and young permanent dentition. In: Hargreaves KM, Cohen S. Cohen's pathways of the pulp. 10th Edition. St. Louis: Mosby Elsevier; 2011: 809.

8. Fuks AB, Peretz B. Pediatric endodontics - Current concepts in pulp therapy for primary and young permanent teeth. Berlin: Springer, 2016.

9. Foley JI. Management of carious primary molar teeth by UK postgraduates in paediatric dentistry. Eur Arch Paediatr Dent. 2010;11:294-297.

10. Ahmed HM. Pulpectomy procedures in primary molar teeth. Eur J Gen Dent. 2014; 3:3-10.

11. Bjorndal L. Stepwise Excavation. Monogr Oral Sci. 2018; 27:68-81.

12. Proz.com. [Online] [Cited: 11 21, 2019.] https://www.proz.com/kudoz/english-toromanian/medical-dentistry/3052937stepwise-excavation.html.

13. Luca R. Pedodonţie (Vol. I). Bucureşti: Ed. Cermaprint, 2003.

14. Luca R. Pedodonţie (Vol. II). Bucureşti: Ed. Cermaprint, 2003.

15. Luca R. Pedodonţie (Vol. III). Bucureşti: Ed. Cermaprint, 2013.

16. Muntean A, Mesaros AS, Festila D, Mesaros M. Modern management of dental decay in children and adolescents - a review. Cluj Medical. 2015; 88(2):137-139.

17. McDonald RE, Avery DR, Dean JA. Dentistry for the child and adolescent. 8th ed. St. Louis: Mosby Inc; 2004:p.236-257, 257- 270, 333-353, 353-364.

18. Blique M. Prophylaxie dentaire individuelle, nouvel outil pour le traitement du jeune enfant a risque carieux eleve. J Odontol Pediatr. 1999;9:9-14.

19. Poutanen R, Lahti S, Seppä L, Tolvanen M, Hausen $\mathrm{H}$ : Oral health-related knowledge, attitudes, behavior and family characteristics among Finnish schoolchildren with and without active initial caries lesions. Acta Odontol Scand. 2007; 65:87-96.

20. Fejerskov $O$. Changing paradigms in concepts on dental caries: Consequences for oral health care. Caries Res. 2004; 38:182-191.

21. Rodd $H$, Wray A. Treatment Planning for the Developing Dentition. London: Quintessence publishing Co. Ltd; 2006: 45-73.

22. Samardi R, Gabre P, Gahnberg L. Strategies for caries risk assessment in children and adolescent at public dental clinics in a Swedish country. Int J Paediatr Dent. 2009;19(2):135-140.

23. Zukanovic A. Caries risk assessment models in caries prediction. Acta Medica Academica. 2013;42(2):198-208. 